\title{
Ensino de Inglês para fins acadêmicos a alunos de pós-graduação: percepções, desafios e ações em curso
}

\author{
Jânderson Albino Coswosk ${ }^{1}$
}

\begin{abstract}
Resumo
Esta narrativa de ensino tem a finalidade de explorar a criação e implantação de um curso de inglês para fins acadêmicos voltado às Ciências Exatas e Agrárias, direcionado aos mestrandos do Programa de Pós-Graduação Stricto Sensu em Agroecologia (PPGA), do Instituto Federal do Espírito Santo (Ifes) - Campus de Alegre. Nessa perspectiva, a narrativa esboça i) os objetivos de formatação e implantação de um curso prévio de inglês para fins acadêmicos para os alunos do PPGA, tendo em vista a heterogeneidade do grupo e a diversidade dos objetivos acadêmicos dos ingressantes e ii) a percepção dos discentes quanto à possibilidade de assimilação do conhecimento técnico-agrário em inglês a partir do curso. A narrativa se estrutura em metodologia híbrida e interpretativista $e$ indica resultados que fomentam a necessidade da institucionalização da língua inglesa enquanto uma das disciplinas-chave do mestrado, bem como de ferramenta de internacionalização e divulgação do conhecimento produzido por alunos e professores do PPGA.
\end{abstract}

Palavras-chave: Inglês para fins acadêmicos. Conhecimento agroecológico em língua inglesa. Percepções e ações em curso.

\begin{abstract}
The following teaching narrative intends to explore the creation and implementation of an English for academic purposes (EAP) course related to Exact and Agrarian Sciences, focused on graduate students of the Master's Program in Agroecology (PPGA), from the Federal Institute of Espírito Santo (Ifes), based in Alegre, Espírito Santo, Brazil. By doing so, the narrative highlights i) the aims of designing and implementing a previous EAP course for PPGA's students, considering heterogeneous and diverse academic purposes as its driving force and ii) the students' perception when it comes to the assimilation of agrarian knowledge available in English taking into account the course. A hybrid and interpretativist methodology indicates the need for institutionalizing English as one of the PPGA's key disciplines, as well as a tool for internationalization and dissemination of knowledge produced by its students and professors.
\end{abstract}

Keywords: English for academic purposes. Agroecological knowledge in English. Perceptions and works in progress.

\section{Introdução}

Oriunda de sua versão lato sensu, implantada no Ifes - Campus de Alegre em 2010, a formatação do Programa de Pós-graduação stricto sensu em Agroecologia teve início em 2016, após aprovação da Coordenação de Aperfeiçoamento de Pessoal de Nível Superior CAPES no ano anterior. Ofertado anualmente na modalidade de Mestrado Profissional em Agroecologia, o curso possui amplitude, corpo docente e linhas de pesquisa bastante diversos,

\footnotetext{
${ }^{1}$ Doutorando em Literaturas de Língua Inglesa (UERJ). Instituto Federal do Espírito (Ifes) - Campus de Alegre. E-mail: jandersoncoswosk@gmail.com
} 
o que constitui uma oferta que abrange desde profissionais das Ciências Agrárias, até aqueles das Ciências Exatas, Biológicas e áreas afins.

O escopo inter e transdisciplinar do curso em evidência é fruto do que têm constituído os estudos em torno da Agroecologia desde a década de 1990, momento em que o vocábulo começou a figurar de modo mais intenso em publicações acadêmicas, bem como nas práticas agrícolas. Desde 1960, o termo “Agroecologia" ganhou um caráter polissêmico, já que pode ser entendido tanto como ciência, quanto como movimento e prática (WEZEL at al., 2009; GÓMEZ; RÍOS-OSORIO; ESCHENHAGEN, 2013). As mudanças semânticas a ele agregadas, pensadas sob diferentes perspectivas a partir da década de 1960, ocorreram devido a uma polissemia sistêmica que o envolve, já que não podemos encará-la apenas como uma disciplina científica, mas como um processo dinâmico que envolve aspectos ambientais, sociais, econômicos, éticos e de desenvolvimento, embora tenha como primazia o envolvimento de uma série de abordagens que buscam a resolução dos desafios reais da produção agrícola (NORDER et al., 2016).

A variação do que se entende por "Agroeocologia", conforme apontam Gómez, RíosOsorio e Eschenhagen (2013), ainda é uma questão mundial e tem sido refletida em inúmeras publicações das últimas décadas do século XX e das duas primeiras do XXI (HECHT, 1995; WEZEL et al., 2009; TOMICH et al., 2011). No que diz respeito à Agroecologia nos Estados Unidos, por exemplo, país onde se concentra a maior produção acadêmica sobre o assunto, ela contribuiu para o surgimento, definição e consolidação do conceito de agricultura sustentável. Dessa forma, as definições iniciais de agroecologia foram expandidas para a ecologia dos sistemas alimentares devido ao uso intensivo de pesticidas e sua evidência negativa, suscitada pelo estudo da agricultura ecológica, aliada ao conhecimento avançado em biologia.

Ao contrário do que ocorre nos Estados Unidos, a agroecologia fundou-se no Brasil a partir de práticas agrícolas tradicionais, de políticas governamentais, do sistema curricular da educação formal brasileira, de conceitos que associam a agroecologia a um modo de vida, à ética, e não apenas à ciência, considerando que ela passou a ser vista como um movimento de retorno às raízes dos povos da América Latina, de forma a combater uma agricultura baseada no uso intensivo de defensivos agrícolas (GÓMEZ; RÍOS-OSORIO; ESCHENHAGEN, 2013; NORDER et al., 2016). 
O dinamismo do quadro teórico-crítico em que se estabelece a Agroecologia não impactou apenas a formatação do curso de mestrado homônimo ao termo, mas atingiu diretamente o processo seletivo deste a partir de sua implantação. A análise aqui apresentada não leva em consideração a obviedade da diversidade de projetos de dissertação submetidos ao PPGA ao longo desses anos, mas chama a atenção, inicialmente, para uma das etapas desta seleção: o exame de proficiência em língua inglesa (EPLI).

Diante do baixo índice de aprovação dos candidatos nos testes de proficiência em LI, decorrente de inúmeros fatores socioeducacionais a serem explorados mais a frente $e$, percebendo o caráter obrigatório da avaliação para a entrada no curso, o pesquisador pensou, em consonância à coordenação do mestrado, numa proposta de oferta de um curso de inglês para fins acadêmicos aplicado às Ciências Agrárias e Exatas, que sanasse a dificuldade dos alunos com a leitura de textos de áreas correlatas à Agroecologia em língua adicional (LA) e que conhecessem, ao longo do curso, estratégias e ferramentas de leitura e interpretação de artigos e periódicos especializados para a avaliação e as possíveis publicações decorrentes de suas pesquisas em curso. Isso influenciaria também no fluxo de entrada dos candidatos, uma vez que o teste passou a ser aplicado no decorrer do primeiro semestre letivo, não mais antes do resultado do processo seletivo.

Assim, esta narrativa de ensino investe na reflexão sobre a presença do inglês enquanto LA no curso de mestrado profissional do Ifes - Campus de Alegre, com base na implantação do curso de inglês para fins acadêmicos. Dentro de um framework temporal que compreende os anos 2016 a 2019, a análise investe numa reflexão sobre os objetivos de implantação, organização teórico-metodológica e montagem do curso Inglês aplicado às Ciências Exatas e da Terra, bem como os desdobramentos iniciais dessas ações, tendo em vista o perfil socioeducacional do corpo discente e os desafios pretéritos e contemporâneos encontrados pelos alunos face à necessidade de aprendizado do inglês em caráter instrumental e a deficiência que os acompanham ao longo da vida acadêmico-escolar.

Para tal, o estudo em tela também se estrutura a partir de análise de dados coletados junto ao site do PPGA, referentes ao interstício entre 2016 a 2019. A fim de aprofundarmos nossas impressões sobre os dados coletados nas fontes mencionadas, valemo-nos, ainda, de um questionário estruturado (GIL, 1999), hospedado na ferramenta online Google Forms ${ }^{\oplus} \mathrm{e}$ aplicado a 31 alunos, matriculados entre os anos 2016 (4 dos respondentes), 2017 (6 dos 
respondentes), 2018 (9 dos respondentes) e 2019 (12 dos respondentes), tendo participado ou não do curso implantado em 2017. Os dados compilados foram apresentados de maneira não linear na narrativa, distribuídos nas duas etapas em que a discussão ocorre. Inicialmente, apresentamos as motivações que levaram em consideração a implantação do curso Inglês Aplicado às Ciências Exatas e da Terra, contextualizando as demandas pelo curso, sua formatação e implantação.

A narrativa utilizou um formato metodológico híbrido e interpretativista (MOITA LOPES, 1994; DORNYEI, 2007), a fim de que os dados coletados e analisados pudessem iluminar as seguintes questões, que continuam em pauta como norteadoras de ações futuras a serem implantadas no PPGA: o curso foi capaz de sanar as necessidades de leitura instrumental dos alunos, a ponto de auxiliá-los no processo de ingresso no PPGA? Sendo positiva a resposta à pergunta anterior, ele pode estimulá-los à leitura e citação de textos em língua adicional durante a pesquisa de mestrado? Houve, ainda, alterações no número de publicações em inglês dos alunos e estímulo para participação em eventos internacionais, derivados do curso, tendo em vista que o conhecimento agroecológico ainda possui o inglês enquanto língua hegemônica nas publicações acadêmicas (GÓMEZ; RÍOS-OSORIO; ESCHENHAGEN, 2013, p. 357)?

2 Pensando o curso: modelagem, implantação e tensões envolvidas

As questões anteriormente suscitadas trilharam um enorme percurso temporal até chegarem às linhas que lhe couberam. Sendo o primeiro curso stricto sensu do Ifes - Campus de Alegre e não estando distante da realidade de seleção dos cursos de pós-graduação das instituições federais de ensino, nos quais possuem um exame próprio, o PPGA estabeleceu o inglês como LA de seu exame de proficiência linguística realizado pelos candidatos ao mestrado em seu ano inaugural ${ }^{2}$.

Um enorme desafio para os alunos, docentes e coordenadoria do programa ficou mais explícito assim que os resultados do EPLI referente ao ingresso em 2016 foram tabulados. 0 abalo estatístico com os resultados do EPLI-2016 revelava tanto um quadro menor da

\footnotetext{
2 O EPLI ocorre com frequência semestral, tendo o aluno a chance de realizá-lo até duas vezes (no primeiro ou segundo semestre letivo do mestrado).
} 
realidade capixaba, visto que a maior parte dos alunos do PPGA são do Espírito Santo, conforme aponta o Gráfico 1, quanto um quadro maior de país.

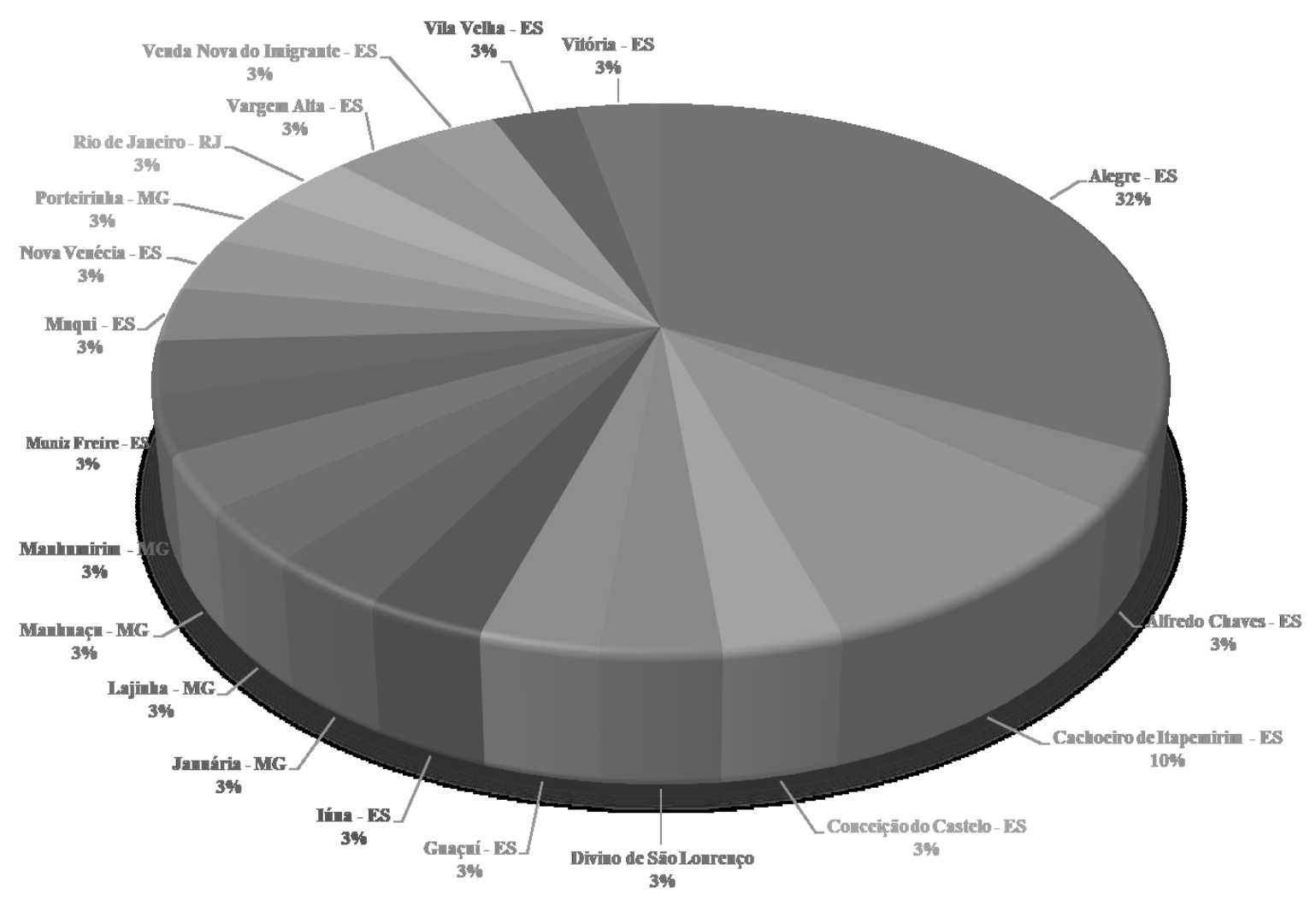

\begin{tabular}{|l|r|}
\hline Municípios Atendidos & Mestrandos \\
\hline Alegre - ES & 10 \\
\hline Alfredo Chaves - ES & 1 \\
\hline Cachoeiro de Itapemirim - ES & 3 \\
\hline Conceição do Castelo - ES & 1 \\
\hline Divino de São Lourenço - ES & 1 \\
\hline Guaçuí - ES & 1 \\
\hline Iúna - ES & 1 \\
\hline Januária - MG & 1 \\
\hline Lajinha - MG & 1 \\
\hline Manhuaçu - MG & 1 \\
\hline Manhumirim - MG & 1 \\
\hline Muniz Freire - ES & 1 \\
\hline Muqui - ES & 1 \\
\hline Nova Venécia - ES & 1 \\
\hline Porteirinha - MG & 1 \\
\hline Rio de Janeiro - RJ & 1 \\
\hline Vargem Alta - ES & 1 \\
\hline Venda Nova do Imigrante - ES & 1 \\
\hline Vila Velha - ES & 1 \\
\hline Vitória - ES & 1 \\
\hline Total & 31 \\
\hline
\end{tabular}

Gráfico 1. Média comparativa dos municípios mais atendidos pelo PPGA de 2016 a 2019. Fonte: Questionário de Percepção Discente - PPGA, Ifes - Campus de Alegre. 
O inglês tem figurado de forma majoritária nos currículos das escolas de educação básica, com a obrigatoriedade do ensino de LA na última fase do ensino fundamental e durante o ensino médio a partir do que estabelecem os Parâmetros Curriculares Nacionais PCN (BRASIL, 1998). Durante 21 anos, esteve em vigor também o Art. 26 - $\int 5^{\circ}$ da Lei de Diretrizes e Bases da Educação Nacional (1996), que estabelecia a obrigatoriedade do ensino de uma LA a partir da segunda etapa do ensino fundamental, permitindo a comunidade escolar escolher qual ofertaria, de acordo com suas condições (BRITISH COUNCIL, 2015). 0 texto foi alterado pela Lei $n^{0} 13.415$, de 16 de fevereiro de 2017 , conferindo obrigatoriedade ao ensino de inglês a partir do sexto ano do ensino fundamental (QUEVEDO-CAMARGO; SILVA, 2017).

A abordagem dos PCNs quanto ao ensino de LA corroborou no uso do inglês e do espanhol na reformulação do Exame Nacional do Ensino Médio (ENEM), em 2010, quando este se tornaria a porta de entrada para as instituições federais de ensino superior e forma de seleção de bolsistas para cursos de graduação em instituições particulares de ensino, uma vez que sua relevância a partir do exame de 2010 seria maior (BLANCO, 2013). Outro fator relevante a ser considerado é o uso da LA no ENEM com a livre escolha do candidato pela LI ou espanhola. Embora o ensino de LI seja majoritário nas escolas públicas e privadas brasileiras, a escolha pelo espanhol prevalece nas inscrições para o exame (FONSECA, 2016).

Dados os fluxos de mercadorias, pessoas, símbolos e de conhecimento pelo mundo, a necessidade de internacionalização das instituições federais de ensino superior tornou-se uma pauta cada vez mais constante do Ministério da Educação (MEC) e da CAPES. Diante do quadro de expansão em que se encontrava o ensino superior da rede federal, principalmente no final da primeira década e início da segunda de nosso século e, tendo em vista a hegemonia do inglês nas Relações Internacionais e naquelas que já permeavam a pesquisa, a extensão e o ensino brasileiros, o MEC e a CAPES instituíram os programas de intercâmbio Ciências sem Fronteiras (CSF) e o Idiomas sem Fronteiras (ISF) (DE ABREU-E-LIMA et al., 2017).

Ambos os programas levantaram questões que se perpetuam aos nossos dias sobre a demanda pelo inglês enquanto língua hegemônica dos cursos de pós-graduação no Brasil e seu impacto nesses cursos em decorrência da criação CsF e do IsF, que buscaram estimular a mobilidade acadêmica de graduandos brasileiros em instituições estrangeiras (BAFFI- 
BONVINO; CASANOVA; ZORZETTO, 2017). Como parte integrante do IsF e CsF, houve a implantação do curso My English Online (MEO), onde alunos de graduação e pós-graduação, de instituições públicas e privadas, podem estudar inglês virtual e gratuitamente e obterem a certificação de proficiência em língua inglesa. Além disso, o governo disponibilizou gratuitamente exames do TOEFL ${ }^{\oplus}$ (Test of English as a Foreign Language) para os estudantes que desejavam obter experiência acadêmica em universidades estrangeiras, cuja aceitação do teste em evidência é um dos requisitos para o ingresso de alunos estrangeiros em universidades europeias e, principalmente, norte-americanas.

Conforme abordamos brevemente, o governo federal passou a desenvolver políticas linguísticas de ensino de inglês enquanto LA desde o final do século XX, sem deixar, entretanto, de criar ao redor delas enormes lacunas que se formaram ao longo da implantação de tais medidas. O desafio enfrentado pelo PPGA em ter de lidar com um déficit de proficiência em inglês considerável por parte de seus alunos é fruto de um enorme paradoxo criado no interior dessas políticas linguísticas: se, por um lado, temos um investimento considerável nas universidades em termos de cursos que aprimorem a proficiência de alunos da educação superior em língua inglesa, dada a grande demanda pela língua, por outro, temos enormes percalços que envolvem o ensino de LI na educação básica.

Em análise ao sistema brasileiro de educação e o ensino de LI nas escolas públicas, 0 British Council (2015) publicou em relatório que o ensino de inglês, bem como de qualquer outra disciplina escolar, sofre um enorme impacto devido à própria estrutura de funcionamento das escolas municipais, estaduais e federais, bem como a vulnerabilidade social que os alunos estão acometidos dentro e fora do ambiente escolar, a heterogeneidade e o excesso de alunos em sala de aula, a falta de recursos didáticos e humanos, tendo em vista a precarização dos salários dos professores e condições de trabalho. Além disso, os alunos chegam à segunda etapa do ensino fundamental com problemas básicos de leituras e escrita. Tal quadro não foge à realidade que enfrentamos em nosso meio, considerando que mais de $70 \%$ de nossos alunos concluíram o ensino fundamental e médio em instituições públicas e não estão distantes das transformações descritas anteriormente no que tange ao ensino de LI no Brasil, já que um grande percentual finalizou o ensino médio entre 1996 a 2015, conforme aponta o Gráfico 2. 


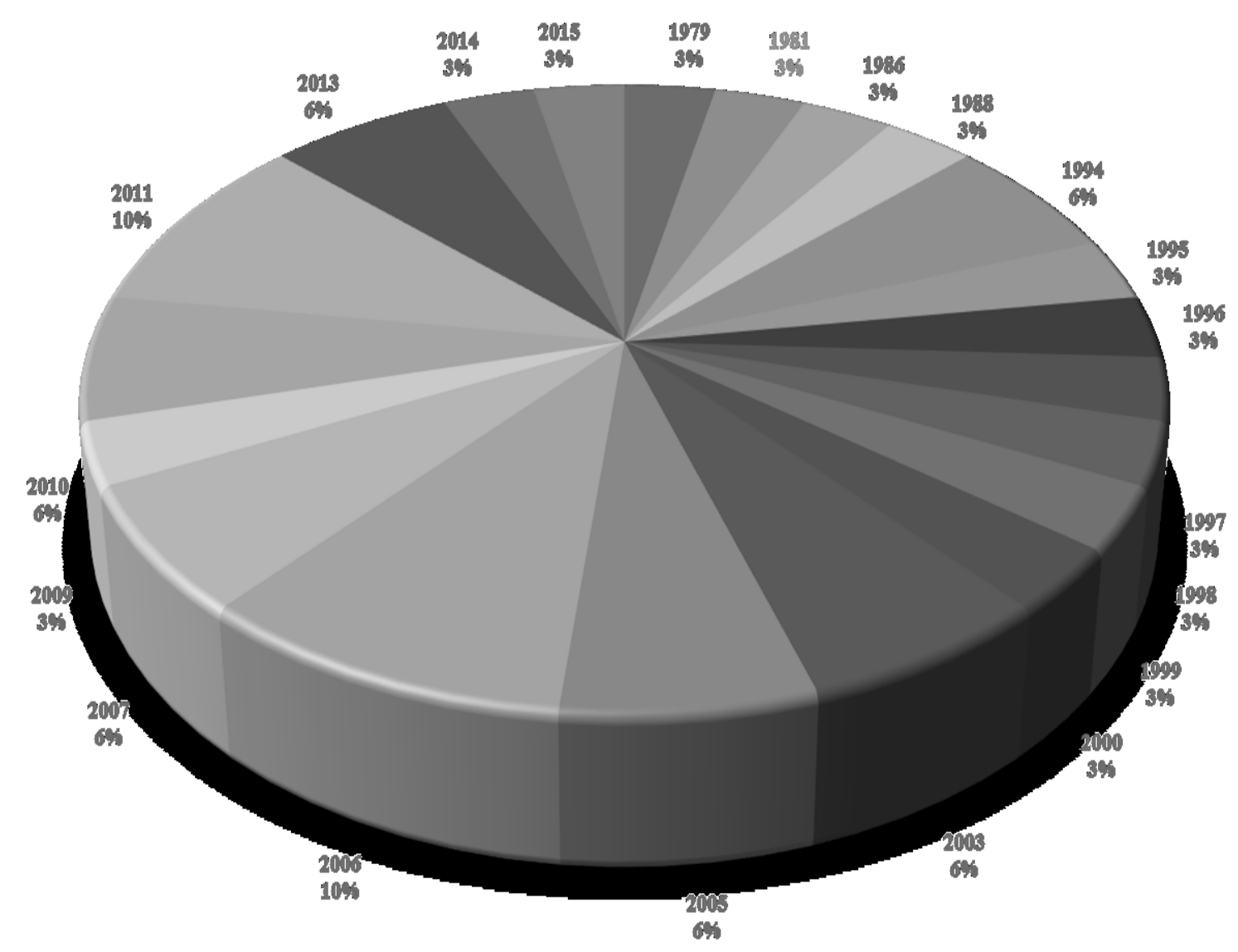

\begin{tabular}{|r|r|}
\hline Término do Ensino Médio & Mestrandos \\
\hline 1979 & 1 \\
\hline 1981 & 1 \\
\hline 1986 & 1 \\
\hline 1989 & 1 \\
\hline 1994 & 2 \\
\hline 1995 & 1 \\
\hline 1996 & 1 \\
\hline 1997 & 1 \\
\hline 1998 & 1 \\
\hline 1999 & 1 \\
\hline 2000 & 1 \\
\hline 2003 & 2 \\
\hline 2005 & 2 \\
\hline 2006 & 3 \\
\hline 2007 & 2 \\
\hline 2009 & 1 \\
\hline 2010 & 2 \\
\hline 2011 & 3 \\
\hline 2013 & 2 \\
\hline 2014 & 1 \\
\hline 2015 & 13 \\
\hline & \\
\hline
\end{tabular}

Gráfico 2. Média comparativa dos alunos do PPGA em relação ao término do Ensino Médio. Fonte: Questionário de Percepção Discente - PPGA, Ifes - Campus de Alegre. 
De 2015 até o momento presente, o Brasil ainda continua a figurar entre os países com baixa proficiência em LI, de acordo com a edição 2019 do Índice de Proficiência em Inglês (English Proficiency Index) divulgado pela EF Education First. O Brasil registrou a pontuação 50,10, menor que os índices de 2017 e 2018 , passando de $41^{\mathrm{a}}$, em 2017 , para a $59^{\mathrm{a}}$ posição em 2019 (EF, 2019).

Na trilha de Baffi-Bonvino, Casanova e Zorzetto (2017), tomamos a experiência do EPLI como um diagnóstico que vai além de uma amostra que determina ou não a proficiência linguística dos candidatos ao mestrado em Agroecologia. Decidimos acolher os resultados como tomada de decisão a respeito do planejamento curricular, bem como do preparo dos discentes para o exame através da implantação do curso Inglês aplicado às Ciências Exatas e da Terra. 0 projeto do curso foi pensado, inicialmente, de modo a sanar o impasse entre a realização do EPLI e o estímulo à entrada dos alunos.

Compreendemos a formalização do projeto do curso via Direção de Ensino do Ifes Campus de Alegre e Pró-Reitoria de Ensino do Instituto Federal do Espírito Santo como uma maneira de levarmos em consideração todo um questionamento teórico-crítico em torno da noção de "especificidade" debatida por Hyland (2016), concernindo a formatação de cursos de inglês para fins acadêmicos. 0 estudo do inglês com este propósito compreende usos específicos e intencionais da linguagem, o que implica num design de curso que englobe 0 uso da língua-alvo nas mais diversas áreas científicas que o compõem e que contemple a heterogeneidade do público-alvo, sua formação básica e superior, a preparação do material didático e a abordagem não só do conhecimento agroecológico em inglês, mas também das ciências exatas e agrárias, de modo geral. O curso não possui caráter compulsório, portanto, todos os alunos matriculados participaram voluntariamente.

A proposta também esteve amparada nos pressupostos de Lillis e Tuckin (2016), que entendem que a leitura e escrita acadêmicas em LA devem ser assinaladas como práticas sociais plurais. Ao situarem o contexto específico a ser abordado, a leitura e a escrita acadêmicas em LA devem sinalizar discussões em torno de estruturas e relações de poder, tendo em vista as diversas agendas do campo agroecológico em torno da melhoria e qualidade de vida das populações ao redor do globo, as relações de gênero, econômicas, políticas e ecológicas que moldam esses processos e que ultrapassam o universo acadêmico. 
Em linhas gerais, o curso estabeleceu uma metodologia participativa que privilegiasse o desenvolvimento da habilidade da leitura, por meio do conhecimento e do uso das estratégias de compreensão dos textos. Para tanto, o método pressupôs:

1. Levantamento das necessidades e dificuldades dos alunos;

2. Definição dos textos e atividades-meio a serem trabalhados;

3. Acompanhamento sistemático do processo de produção dos alunos;

4. Fornecimento das condições de trabalho para que os alunos se tornassem leitores autônomos;

5. Avaliação do desempenho dos alunos, através da solução de tarefas que possibilitem o uso das estratégias de leitura e compreensão desenvolvidas nas aulas.

Não obstante, buscamos formular um material que fosse de encontro às necessidades de leitura e interpretação dos educandos, mas que pusesse em jogo olhares críticos sobre os textos lidos, estimulasse quadros comparativos de dados, bem como a aquisição de vocabulário acadêmico dos campos mencionados (GABLASOVA, 2015; COXHEAD, 2016), abrindo caminhos para que os alunos pudessem criar uma autonomia ao lidarem com textos e linguagem acadêmica em LA. No preparo do material, consideramos como público-alvo alunos com nível $\mathrm{Al}$ do Quadro europeu comum de referência para as línguas, isto é, “capaz[es] de compreender[em] nomes conhecidos, palavras e frases muito simples, por exemplo, em avisos, cartazes ou folhetos" (CONSELHO DA EUROPA, 2001, p. 53). Levamos em conta que a maioria dos alunos teve contato bastante insipiente com a língua e que 0 ensino de inglês para fins acadêmicos se difere em abordagem e material didático daquele que os alunos geralmente têm contato durante o ensino fundamental e médio e em cursos privados (HUTCHINSON; WATERS, 1987; HYLAND, 2016).

Na esteira de Crawford (1995), criamos um formato de curso e de material didático que mostrassem em sua construção a ausência de neutralidade e a exigência da criticidade para com os textos, imagens, atividades e metodologia aplicada; que trouxessem modelos linguísticos e culturais adequados ao contexto, mas que não engessassem os alunos somente àqueles apresentados e que pudessem, em suma, comungar com a realidade acadêmicoprática dos mestrandos do PPGA. 
O desafio docente com a familiarização da linguagem acadêmica das Ciências Exatas e Agrárias e o maior foco na polissemia que envolve o conhecimento agroecológico conferiu ao curso um tom mutante, tornando-o passivo de reelaborações e acréscimos a cada turma, para atender ainda mais as necessidades e diversidade de cada grupo acolhido. Tais traços foram reveladores no questionário aplicado aos alunos, tornando ainda mais transparentes as impressões colhidas pelo professor e idealizador do curso, que serão discutidas a partir dos dados coletados.

\section{Percepções discentes: trajetórias acadêmicas e impactos no PPGA}

Conforme salientamos no início desta reflexão, o questionário aplicado visou muito mais do que coletar impressões dos alunos acerca dos índices de aprovação nos EPLI, sobretudo aos alunos que puderam participar da empreitada. Depois de um quadro de três anos do projeto em curso, foi necessário traçar um perfil mais detalhado de nosso públicoalvo, que já vem sendo explicitado desde nossas primeiras reflexões aqui traçadas, de modo a pensarmos sobre possíveis acertos e falhas quanto a necessidade dos alunos em relação ao aprendizado do inglês enquanto língua franca da academia (MAURANEN, 2016).

Nosso principal anseio foi mostrá-los de que modo o estudo do inglês com propósitos específicos pode aumentar a oportunidade de acesso ao conhecimento agroecológico publicado ao redor do mundo, não somente aquele disponível na língua materna. Além disso, queríamos mostrar que há possibilidade de criarmos uma faceta mais ampla do curso ofertado, possibilitando aos alunos a aprimorarem outras habilidades linguísticas necessárias ao aprendizado de qualquer LA, principalmente a escrita, no caso em questão.

Além de perguntas que definem um quadro de vida acadêmica que antecede a vivência no PPGA, os alunos se posicionaram acerca da participação em programas de internacionalização durante a graduação e o mestrado, da possível participação no curso My English Online, além de relatarem uma provável participação em cursos privados de inglês e a necessidade da língua durante toda a pesquisa do mestrado.

Algumas dessas perguntas não obtiveram o posicionamento dos 31 respondentes, uma vez que entre eles há alunos que não puderam realizar o curso. Garantimos a possibilidade de resposta a esses alunos porque também precisávamos ter uma ideia sobre o outro lado da 
história - uma média de como esses alunos que não puderam se valer do curso seguiram a vida acadêmica durante dois anos.

Dos 31 respondentes, apenas I participou de programas/ações de internacionalização durante a graduação e nenhum durante o mestrado. Em nível macro, quando analisamos a oferta do MEO e a procura em relação aos respondentes, apenas 4 realizaram o curso (2 durante a graduação e 2 durante o mestrado). 0 número de respondentes que indicaram terem frequentado cursos de inglês em escola de idiomas antes do ingresso no mestrado é bastante expressivo, tal como mostra o Gráfico 3.

\begin{tabular}{|l|r|}
\hline $\begin{array}{l}\text { Tempo de curso de idiomas } \\
\text { realizado antes do ingresso no } \\
\text { mestrado }\end{array}$ & Mestrandos \\
\hline 2 anos ou mais & 7 \\
\hline 1 ano & 4 \\
\hline menos de 1 ano & 5 \\
\hline Não realizaram & 15 \\
\hline Total & 31 \\
\hline
\end{tabular}

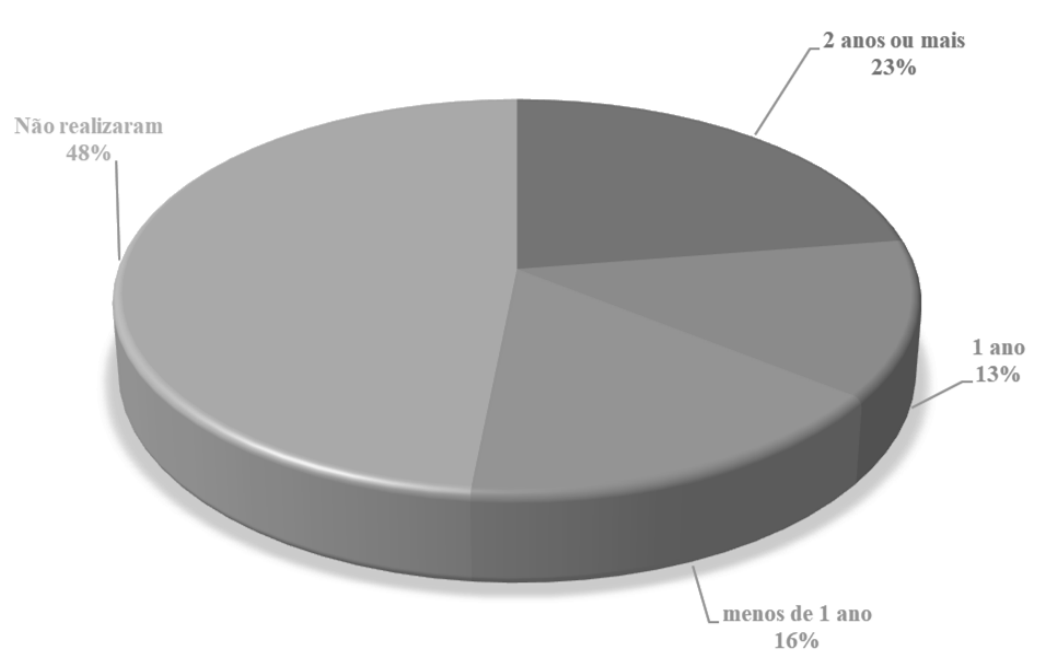

Gráfico 3. Média comparativa dos alunos do PPGA que participaram ou não de curso de inglês em escola de idiomas antes do mestrado.

Fonte: Questionário de Percepção Discente - PPGA, Ifes - Campus de Alegre.

Dentro do montante total apresentado, 17 alunos participaram do curso entre 2017 a 2019. Dos que participaram, apenas um apontou que o curso não teve impacto sobre sua vida acadêmica durante o mestrado. Tal questionamento pode ser colocado à luz do momento pós-curso e EPLI, sobre o qual os alunos responderam se, durante a pesquisa de mestrado, tiveram de ler textos em LI e se a composição da dissertação considerou textos em LI como referências. Apenas 1 dos respondentes afirmou não ter lido textos em LI durante a pesquisa e 4 não responderam. Quanto a citação de textos em inglês na dissertação, 19 alunos responderam de maneira afirmativa, enquanto somente 5 não responderam por motivos 
anteriormente apresentados. A partir deste momento do questionário em diante, todos os casos omissos ou em que houver falta da parte relativa aos respondentes não mencionados na análise se referem aos alunos que ainda se encontram em pesquisa ou no estágio inicial da dissertação.

O número de respondentes que se posicionaram positivamente ao uso de textos em LI em suas pesquisas reverbera com as respostas das 3 últimas questões, relativas a) à metodologia do professor na melhoria da leitura e interpretação de textos em LI, b) ao estímulo à leitura de textos acadêmicos em LI a partir do curso e c) ao impacto do curso na produção escrita em LI. Em se tratando do primeiro tópico, 15 alunos se posicionaram positivamente, enquanto 13 abordaram o segundo tópico de igual modo. Sobre o terceiro item, 14 alunos apontaram que não produziram textos e nem apresentações de trabalho em inglês durante o mestrado.

Expressar em números os pontos mencionados requer uma breve reflexão sobre a produção intelectual dos alunos e docentes do PPGA disponíveis no site do programa. Em se tratando de todas as produções apontadas - publicações discentes em anais, revistas especializadas, boletins técnicos, além do livro Tópicos em Agroecologia Vol. I, organizado por professores e técnicos administrativos do PPGA, nenhuma foi publicada em LA ${ }^{3}$. Em contrapartida, tal expressão numérica requer também a descrição do que o curso, de modo geral, significou para os alunos que dele puderam usufruir. Trazemos, no Q̨uadro 1, alguns excertos das considerações por eles apontadas.

\begin{tabular}{|l|}
\hline A1: ${ }^{4}$ curso ajudou a compreender a necessidade da língua inglesa e a buscar por artigos em inglês, por sua \\
relevância acadêmica. \\
\hline A2: Através do curso, aprendi termos técnicos usados em textos científicos e termos específicos da área de \\
ciências agrárias, além de reforçar a parte ortográfica, verbal e a leitura de textos em geral. \\
\hline A3: Com as técnicas de leitura e interpretação, meu desempenho em compreender um artigo ou texto em \\
língua inglesa foi muito melhor. Inclusive, pude relembrar muita coisa no curso. Ajudou bastante. \\
\hline A4: Durante o mestrado, é necessária a leitura de artigos em inglês e o curso me ajudou, dando uma base \\
para a leitura desses textos, que em muitas vezes elevavam a qualidade do estudo. \\
\hline A5: Nós de escolas públicas dos anos go, não tivemos base nenhuma ou muito pouca da língua inglesa, o \\
que dificultou muito. Mas com o curso do PPGA e o estudo em casa, tudo terminou bem. \\
\hline A6: O curso abordou dicas para auxiliar a interpretação de textos sobre assuntos com os quais não estou \\
habituado a ler. \\
\hline $\begin{array}{l}\text { A7: } 0 \text { curso me auxiliou significativamente a ler textos em língua inglesa durante o mestrado e após o } \\
\text { mesmo e a realizar com sucesso a prova de proficiência. }\end{array}$ \\
\hline
\end{tabular}

\footnotetext{
3 Informações disponiveis em: https://ppga.alegre.ifes.edu.br

4 Os alunos foram representados pela letra "A" e um número.
} 
A8: 0 curso foi decisivo para compreensão dos textos sem o uso do Google tradutor e dicionário, o que me ajudou muito na leitura e compreensão rápida e seleção dos melhores artigos.

Ag: 0 curso facilitou o entendimento de materiais técnicos relacionados à área de atuação do Mestrado. Aı: 0 professor ensinou algumas técnicas de como ler artigos em inglês, o que facilitou a interpretação/entendimento, possibilitando ler mais trabalhos em inglês, aumentando o referencial teórico da minha dissertação (uso essas dicas até hoje).

Quadro 1. Impactos do curso na vida acadêmica dos alunos durante o mestrado Fonte: Questionário de Percepção Discente - PPGA, Ifes - Campus de Alegre.

Os comentários atestam uma recepção positiva do curso Inglês aplicado às Ciências Exatas e da Terra, destacando a necessidade da LI e da leitura de textos escritos em LA, convergindo para a necessidade de maiores iniciativas que compreendem o uso da língua dentro do contexto do mestrado $(A 1, A 2, A 4, A 8$ e Ag). Conforme apontamos, embora alguns alunos tenham realizado curso de inglês em escolas de idiomas ou tenham tido um aprendizado significativo da língua em questão no ensino fundamental e médio, o curso conseguiu resgatar desses alunos o conhecimento prévio da língua e o aprimoramento com os conteúdos trabalhados (A3).

É mencionada a importância do curso para além do EPLI, o que demonstra uma necessidade de continuidade de expansão dos objetivos e abordagens nele desenvolvidos para trabalhar outras habilidades linguísticas tão importantes quanto a leitura (A7). Por fim, ressaltam a fragilidade do ensino de LI nas escolas públicas dos anos 1990, tal como apontamos nas primeiras análises (A5), bem como os benefícios do curso para a escrita das dissertações e a sequência da vida acadêmica fora do PPGA (Aı).

4 Considerações preliminares e desafios a frente

Por mais que o inglês seja a LA mais ensinada nas instituições de ensino no Brasil, vários fatores contribuem para que o déficit do aprendizado da LI só seja percebido, analisado e, muitas vezes, levado em consideração por políticas linguísticas governamentais no ensino superior. A mudança profunda operada nas universidades e institutos federais em razão da internacionalização de suas práticas de ensino, pesquisa e extensão levaram à criação de medidas radicais no ensino de LI no Brasil, mas que, muitas vezes, esbarram na dificuldade dos alunos ingressantes em lidar com o conhecimento produzido em LI por não contarem com um arcabouço linguístico satisfatório da língua-alvo. 
Em tempos de globalização e de criação contínua de ações que visam a internacionalização, é mister que os programas de graduação e pós-graduação tomem medidas efetivas para o tratamento do ensino de LI não como um componente extra curricular, mas como garantia de acesso por parte dos alunos a uma produção acadêmica em LI que se faz paralela àquela em que mantêm contato na língua materna.

No caso específico do PPGA, os dados aqui compilados e analisados apontam para a institucionalização do inglês como disciplina e a desarticulação do curso como ferramenta estrita de leitura de textos em LI, ou como instrumento apenas para a realização dos EPLI. Os desafios e tendências do presente apontam para um futuro onde a LI pode servir de veículo da produção acadêmica do PPGA em espaços transnacionais.

Com base nas análises elaboradas e nos perfis traçados, tendo o ensino de inglês para fins acadêmicos como recurso-fim do que objetivamos delinear, podemos responder, junto ao PPGA, às questões colocadas na introdução da narrativa e às demandas que o programa tem levantado ao longo desses poucos anos em termos de seu público-alvo, de internacionalização, da produção intelectual, da promoção da mobilidade acadêmica, no intercâmbio de alunos e docentes do programa com instituições e pesquisadores estrangeiros, da estrutura curricular do curso de mestrado profissional em Agroecologia e de futuros estudos de demanda para a criação de seu respectivo curso de doutorado.

\section{Referências}

BAFFI-BONVINO, M. A.; CASANOVA, G. D.; ZORZETTO, M. S. Reflexões acerca da proficiência em língua inglesa por professores em formação: impacto e efeito retroativo do Programa Idiomas sem Fronteiras. Revista Letras Raras, v.6, n.1, 2017, p. 128-150.

BLANCO, J. A avaliação de língua inglesa no Enem: efeitos de seu impacto social no contexto escolar. Dissertação de mestrado. Programa de Pós-graduação em Linguística - UfsCar. São Carlos, 2013.

BRASIL. Parâmetros curriculares nacionais: terceiro e quarto ciclos do ensino fundamental: introdução aos parâmetros curriculares nacionais. Brasília: MEC/SEF, 1998. 
BRITISH COUNCIL. O Ensino de Inglês na Educação Pública Brasileira. Elaborado com exclusividade para o British Council pelo Instituto de Pesquisas Plano CDE. São Paulo: British Council, 2015.

CONSELHO DA EUROPA. Q̨uadro europeu comum de referência para as línguas: Aprendizagem, ensino, avaliação. Lisboa: Edições Asa, 2001.

COXHEAD, A. Acquiring academic and disciplinary vocabulary. In: HYLAND, K.; SHAW, P. (Eds.). The Routledge handbook of English for academic purposes. London; New York: Routledge, 2016, p. 177-190.

CRAWFORD, J. The Role of Materials in the Language Classroom: Finding the Balance. TESOL in Context, v. 5, n. 1,1995, p. 25-33. Disponível em: https://search.informit.com.au/documentSummary; $d n=700090350107379$;res=IELHSS. Acesso em: 20 fev. 2020.

DE ABREU-E-LIMA, D. M. et al. O Programa Inglês sem Fronteiras e a política de incentivo à internacionalização do ensino superior brasileiro. In: SARMENTO, S.; DE ABREU-E-LIMA, D.; MORAES FILHO, W. B. (Orgs.) Do Inglês sem Fronteiras ao Idiomas sem Fronteiras. Belo Horizonte: Editora UFMG, 2017. Edição Eletrônica.

DORNYEI, Z. Research methods in applied linguistics: quantitative, qualitative and mixed methodologies. Oxford: Oxford University Press, 2007.

EF - EDUCATION FIRST. EF EPI - Índice de Proficiência em Inglês da EF: Um ranking de 100 países $e$ regiões por domínio da língua inglesa. 2019. Disponível em: https://www.ef.com.br/epi/downloads/. Acesso em: 20 fev. 2020.

FONSECA, A. L. S. B. Inglês: a língua da internacionalização. Interfaces Científicas Educação, v. 4, n. 2, 2016, p. $23-32$.

GABLASOVA, D. Learning technical words through L1 and L2: Completeness and accuracy of word meanings. English for Specific Purposes, v. 39, 2015, p. 62-74.

GIL, A. C. Métodos e Técnicas de Pesquisa Social. São Paulo: Editora Atlas, 1999.

GÓMEZ, L.; RÍOS-OSORIO, L. \& ESCHENHAGEN, M. Agroecology publications and coloniality of knowledge. Agronomy for Sustainable Development, 33, 2013, p. 355-362. 
HECHT, S. B. The evolution of agroecological thought. In: Altieri, M.A. (ed) Agroecology: the science of sustainable agriculture. Westview: Boulder, 1995, p 1-19.

HUTCHISON, T.; WATERS, A. English for specific purposes. Cambridge: Cambridge University Press, 1987.

HYLAND, K. General and specific EAP. In: HYLAND, K.; SHAW, P. (Eds.). The Routledge handbook of English for academic purposes. London; New York: Routledge, 2016, p. 17-29.

LILLIS, T.; TUCKIN, J. Academic literacies: A critical lens on writing and reading in the academy. In: HYLAND, K.; SHAW, P. (Eds.). The Routledge handbook of English for academic purposes. London; New York: Routledge, 2016, p. 30-43.

MAURANEN, A.; HYNNINEN, N; RANTA, E. English as the academic lingua franca. In: HYLAND, K.; SHAW, P. (Eds.). The Routledge handbook of English for academic purposes. London; New York: Routledge, 2016, p. 44-54.

MOITA LOPES, L. P. Pesquisa Interpretativa em Linguística Aplicada: a linguagem como condição e solução. D.E.L.T.A., v. 10, n. 2, 1994, p. 329-338.

NORDER et al. (2016). Agroecologia: Polissemia, Pluralismo e Controvérsias. Ambiente \& Sociedade, v. XIX, n. 3, 2016, p. 1-20.

Q̨UEVEDO-CAMARGO, G.; SILVA, G. O inglês na educação básica brasileira: sabemos sobre ontem; e quanto ao amanhã?. Ensino e Tecnologia em Revista, v. 1, n. 2, 2017, p. 258-271.

TOMICH, T. P. et al. Agroecology: a review from a global-change perspective. Annual Review of Environment and Resources, v. 36, 2011, p. 193-222.

WEZEL, A. et al. Agroecology as a science, a movement and a practice. A review. Agronomy for Sustainable Development, 29, 2009, p. 503-515.

Data de submissão: 13/04/2020. Data de aprovação: 07/05/2020. 